\title{
Cyclosporin as a treatment for interstitial lung disease of unknown aetiology
}

\author{
J A Moolman, P G Bardin, D J Rossouw, J R Joubert
}

\begin{abstract}
Ten patients with progressive, symptomatic interstitial lung disease of unknown aetiology who were treated with cyclosporin A were reviewed. Five had clinical and histopathological features of cryptogenic fibrosing alveolitis and five a progressive restrictive lung disease characterised by interstitial infiltration with lymphocytes and minimal fibrosis, which could not be classified precisely. Three patients with lymphocytic infiltration showed a response to initial treatment with cyclosporin $A$ alone at high dosage, but toxicity precluded further treatment. All 10 patients then received low doses of cyclosporin $A$ and prednisone. Three of the patients with cryptogenic fibrosing alveolitis and all five patients with lymphocytic infiltration responded with a reduction in dyspnoea or an increase in vital capacity, or both; cyclosporin $A$ appeared to be effective, or at least to have a corticosteroid potentiating effect. A high incidence of side effects occurred, though these do not necessarily prohibit the long term use of cyclosporin $A$ when it is indicated clinically. Cyclosporin A may be effective in the treatment of interstitial lung disease of unknown aetiology. Further studies are required to determine the long term outcome of treatment.
\end{abstract}

Cryptogenic fibrosing alveolitis is a condition of unknown aetiology associated with alveolar inflammation and the formation of new connective tissue. ${ }^{1}$ Mortality is high, half the patients dying within five years of diagnosis. ${ }^{23}$ A more favourable prognosis is associated with a cellular histological pattern, corticosteroid responsiveness, a lesser grade of dyspnoea, and absence of appreciable hypoxaemia. $^{2-4}$

The pathogenesis of cryptogenic fibrosing alveolitis is thought to be disturbed regulation of an inflammatory process following an unidentified insult to the lower respiratory tract. ${ }^{5}$ The pulmonary macrophage may have a role in causing tissue damage and fibrosis by stimulating fibroblast replication. ${ }^{56} \mathrm{~T}$ lymphocytes may also play a part in an autoimmune reaction against alveolar "self antigen"7 and in promoting fibroblast proliferation. $^{8}$

The aim of treatment is to suppress the inflammatory process and limit alveolar injury and fibrosis. Corticosteroids, the usual treat- ment, produce subjective improvement in about half of the patients and objective improvement in 15\%.24910 Immunosuppressive agents, such as azathioprine, cyclophosphamide, and chlorambucil, may be effective in some patients who fail to respond to corticosteroids $^{11-13}$ and the combination of a corticosteroid and azathioprine or cyclophosphamide may be superior to prednisone alone in slowing progression. ${ }^{11} 1314$

Cyclosporin A reduces the humoral and cellular immune response and may have a role in the treatment of cryptogenic fibrosing alveolitis. ${ }^{6}$ In 10 patients who failed to respond to cyclophosphamide and prednisone transient improvement occurred in some after one to three months' treatment with cyclosporin but no long term benefit was seen. ${ }^{15}$ Treatment with cyclosporin A was successful in a patient with interstitial pneumonitis associated with polymyositis and dermatomyositis. ${ }^{16}$ We have reviewed retrospectively the effect of low doses of cyclosporin A combined with corticosteroids in 10 patients with interstitial lung disease.

\section{PATIENTS}

Patients with a diagnosis of interstitial lung disease of unknown aetiology who were treated with cyclosporin $\mathrm{A}$ at our respiratory clinic during 1978-90 were studied retrospectively. The patients had some of the following clinical features: progressive dyspnoea, bilateral pulmonary crepitations, diffuse bilateral shadowing on the chest radiograph, restrictive lung function, and reduced pulmonary transfer factor. Open lung biopsy confirmed interstitial lung disease in all 10 patients. Bronchoalveolar lavage was performed in nine of the 10 patients at presentation and in nine patients during follow up. On the basis of the initial open lung biopsy five patients (group 1) were diagnosed as having cryptogenic fibrosing alveolitis and five (group 2) an atypical process consisting of a predominant interstitial lymphocytic infiltrate with minimal fibrosis-see table 1.

Group 1 Histology was typical of cryptogenic fibrosing alveolitis ${ }^{1}$ with pulmonary hypertension. The clinical features are shown in table 1 . The patients had a median age of 60 years and had had previous treatment for four to 31 months. At the start of treatment with cyclosporin A with prednisone the degree of dyspnoea was grade III in four cases and grade II in one case (table 2), and all patients had clinical features of pulmonary hypertension. None of the patients had associated disease apart from patient 1 , who had a mixed 
Table 1 Clinical features and bronchoalveolar lavage results at diagnosis and previous treatment regimens in 10 patients with interstitial lung disease of unknown aetiology treated with cyclosporin $A$ and prednisone

\begin{tabular}{|c|c|c|c|c|}
\hline \multirow[b]{2}{*}{ Patient/sex } & \multirow[b]{2}{*}{ Age (y) } & \multirow{2}{*}{$\begin{array}{l}\text { Drug/months of } \\
\text { treatment }\end{array}$} & \multicolumn{2}{|c|}{ BAL: absolute cell count $\star / \%$ of total } \\
\hline & & & Lymphocytes & Neutrophils \\
\hline \multicolumn{5}{|c|}{ Group 1: Cryptogenic fibrosing alveolitis } \\
\hline $\begin{array}{l}1 / F \\
2 / F \\
3 / F \\
4 / F \\
5 / M\end{array}$ & $\begin{array}{l}38 \\
60 \\
67 \\
66 \\
55\end{array}$ & $\begin{array}{l}\mathrm{P}, \mathrm{C} / 30 \\
\mathrm{P} / 31 \\
\mathrm{P} / 6 \\
\mathrm{P} / 4 \\
\mathrm{NT}\end{array}$ & $\begin{array}{c}8 / 6 \\
18 / 13 \\
5 / 7 \\
\text { ND } \\
7 / 13\end{array}$ & $\begin{array}{l}19 / 15 \\
3 / 2 \\
21 / 28 \\
\text { ND } \\
5 / 8\end{array}$ \\
\hline \multicolumn{5}{|c|}{ Group 2: Cellular interstitial lung disease with minimal fibrosis } \\
\hline $\begin{array}{r}6 / F \\
7 / F \\
8 / F \\
9 / F \\
10 / F\end{array}$ & $\begin{array}{l}59 \\
53 \\
43 \\
61 \\
57\end{array}$ & $\begin{array}{l}\mathrm{P} / 86 \\
\mathrm{P}, \mathrm{PL}, \mathrm{A}, \mathrm{C} / 48 \\
\mathrm{P}, \mathrm{A}, \mathrm{C} / 40 \\
\mathrm{P} / 34 \\
\mathrm{NT}\end{array}$ & $\begin{array}{r}314 / 60 \\
117 / 48 \\
103 / 48 \\
252 / 66 \\
92 / 27\end{array}$ & $\begin{array}{c}6 / 2 \\
7 / 3 \\
10 / 5 \\
30 / 8 \\
41 / 12\end{array}$ \\
\hline
\end{tabular}

$\star$ Absolute cell count $\times 10^{6} / 1$ lavage fluid.

P-prednisone; Pl-penicillamine; A-azathioprine; C-cyclophosphamide; CsAcyclosporin A; ND-not done; NT-no treatment.

connective tissue disease with rheumatoid joint lesions. An initial remission in patient 1 was maintained with cyclophosphamide and prednisone treatment. Patients 2, 3, and 4 had deteriorating exercise tolerance and lung function while receiving prednisone at doses of over $20 \mathrm{mg} /$ day. Patient 3 initially responded to prednisone $20 \mathrm{mg} /$ day, but increased doses were ineffective in reversing deterioration.

Group 2 Histological examination showed interstitial lung disease with minimal to mild fibrosis and a prominent lymphocytic infiltrate. These findings were not consistent with any known cause of interstitial lung disease, though they may have represented an early prefibrotic phase of cryptogenic fibrosing alveolitis. Special stains, immunocytochemical investigations with a broad range of monoclonal antibodies, and transmission electron microscopy showed no specific aetiological or morphological features; and clinical and serological investigations, including antigen challenge tests, failed to reveal a cause. Bronchoalveolar lavage showed increased lymphocyte counts (table 1). The median age of the patients was 57 years. The degree of dyspnoea at the beginning of treatment was grade III in four cases and grade II in one

Table 2 Response of 10 patients with interstitial lung disease of unknown aetiology to treatment with cyclosporin $A$ and prednisone

\begin{tabular}{|c|c|c|c|c|c|c|c|}
\hline \multirow{2}{*}{$\begin{array}{l}\text { Time (months): } \\
\text { Patient No }\end{array}$} & & 3 & 6 & 0 & 3 & 6 & \multirow[b]{2}{*}{ Response } \\
\hline & \multicolumn{3}{|c|}{$F V C^{\star}$} & \multicolumn{3}{|c|}{ Dyspnoea ${ }^{\dagger}$} & \\
\hline 1 & 46 & 47 & 51 & 3 & 2 & 2 & Yes \\
\hline 2 & 52 & 62 & 61 & 3 & 3 & 3 & Yes \\
\hline 3 & 77 & 83 & 93 & 3 & 2 & 2 & Yes \\
\hline 4 & 82 & 64 & 75 & 3 & 3 & 3 & Stable \\
\hline 5 & 77 & 56 & 54 & 2 & 3 & 3 & No \\
\hline 6 & 61 & 76 & 84 & 3 & 2 & 2 & Yes \\
\hline 7 & 50 & 59 & 61 & 3 & 2 & 2 & Yes \\
\hline 8 & 47 & 62 & 55 & 2 & 1 & 1 & Yes \\
\hline 9 & 48 & 58 & 60 & 3 & 3 & 3 & Yes \\
\hline 10 & 56 & 62 & 57 & 3 & 2 & 2 & Yes \\
\hline
\end{tabular}

$\star \%$ of predicted forced vital capacity.

† Grade of dyspnoea. case (table 2). Patients 6,7 , and 8 had been treated with high doses of prednisone alone (>20 mg/day) or a combination of corticosteroids and azathioprine, cyclophosphamide, or penicillamine. Decrease or cessation of treatment in these three patients resulted in deterioration of clinical features and lung function. Patient 9 had responded to prednisone ( $>20 \mathrm{mg} /$ day). No patient had had immunosuppressive treatment for at least three months before starting cyclosporin $\mathrm{A}$.

\section{TREATMENT WITH CYCLOSPORIN A}

The trial was approved by the ethical committee of the Faculty of Medicine, University of Stellenbosch. Patients gave written consent after being informed about the experimental nature of the trial. Patients 6,7 , and 8 were treated initially with a single oral dose of cyclosporin A ( $12.5 \mathrm{mg} / \mathrm{kg} /$ day) alone.

Subsequently all 10 patients were treated with a combination of cyclosporin A $7 \mathrm{mg} / \mathrm{kg} /$ day and prednisone $20 \mathrm{mg} /$ day. These doses were maintained for eight to 10 weeks and then reduced slowly over the following two months to a minimum maintenance dose of $3 \mathrm{mg} / \mathrm{kg} /$ day for cyclosporin A and $10 \mathrm{mg} /$ day for prednisone. Combined treatment lasted six to 47 (median 22) months.

Patients were examined clinically at monthly intervals, to determine side effects of cyclosporin A. Serum urea, creatinine, and electrolyte concentrations were determined and a full blood count and liver function tests performed at every visit. Lung function measurements were repeated at monthly intervals and chest radiographs obtained after the first three months and subsequently at six monthly intervals. Vital capacity and forced expiratory volume in one second $\left(\mathrm{FEV}_{1}\right)$ were corrected to BTPS and expressed as a percentage of the predicted value for sex, age, and height. Blood concentrations of cyclosporin A were determined at each visit to check compliance with treatment.

\section{EVALUATION OF RESPONSE}

The response to cyclosporin A treatment was assessed on the basis of symptomatic and physiological criteria. Symptomatic dyspnoea was graded according to the New York Heart Association's criteria. ${ }^{17} \mathrm{~A}$ change of one full grade of dyspnoea constituted a symptomatic response. A $10 \%$ change in forced vital capacity (FVC) constituted physiological improvement or deterioration. ${ }^{2}$ A therapeutic response was defined as a change in dyspnoea or FVC or both at three or six months that persisted for at least three more months. A one grade increase in dyspnoea or a $10 \%$ decrease in FVC maintained for two consecutive months constituted a relapse.

\section{Results}

Patients 6, 7 and 8, who were treated with cyclosporin A alone initially, responded with reduced dyspnoea and an increased FVC. Hypertension and renal impairment developed, however, necessitating a rapid 
reduction of doses. Treatment was withdrawn at the end of a predetermined trial period of nine months. Recurrence of clinical disease and deterioration of lung function occurred in all three patients before combination treatment was started.

EARLY RESPONSE TO COMBINATION TREATMENT (CYCLOSPORIN A AND PREDNISONE)

With combination treatment clinical or lung function improvement, or both, occurred in eight of the 10 patients (table 2 ). Five showed an improvement in both measures and three in one measure. One patient showed a deterioration in both measurements, and one was regarded as stable.

Of the five patients with classical cryptogenic fibrosing alveolitis, three (Nos 1, 2, and 3) responded, but only one (No 3 ) showed an improvement in both symptoms and lung function. All five patients with a cellular histological appearance and minimal fibrosis responded to the combination of cyclosporin $\mathrm{A}$ and prednisone, four showing an improvement in both measurements.

\section{COURSE OF DISEASE AND COMPLICATIONS}

Group 1 One patient (No 1) improved on the combination treatment for 11 months but then deteriorated; she has remained stable for 16 months since the addition of azathioprine. Patient 2 developed severe and resistant hypertension, which caused withdrawal of combination treatment after 17 months, and a subsequent relapse. Patients 3 and 4 died from infection, patient 3 of Klebsiella pneumonia and lung abscesses in pre-existing cystic lesions, and No 4 of septicaemia. Patient 3 had responded to cyclosporin A $3 \mathrm{mg} / \mathrm{kg}$ initially whereas patient 4 had changed to azathioprine one month previously because of no response. Patient 5 did not respond to any immunosuppressants and died one year later.

Group 2 Patients 6 and 8 developed hypertension, which required treatment. Cyclosporin treatment was stopped after 28 months in patient 6 , and she has remained stable for 18 months with low dose prednisone. Patients 7 and 8 relapsed when cyclosporin A withdrawal was attempted after 19 months, and combination treatment was resumed. Renal impairment necessitated withdrawal of treatment in patient 9 after 7 months. Patient 10 remained stable after the initial improvement with combination treatment for a further 18 months.

\section{Discussion}

The patients we studied consisted of two groups, one with classical cryptogenic fibrosing alveolitis and the other with a progressive restrictive lung disease with a lymphocytic interstitial infiltrate of unknown cause. The range of cryptogenic fibrosing alveolitis seen in 42 patients in South Africa did not include cases similar to those seen in group 2, although open lung biopsy specimens were obtained in only seven patients and none underwent bronchoalveolar lavage. ${ }^{18}$

How effective cyclosporin A was in treating the trial group cannot be answered as the patients were also receiving prednisone. The response to cyclosporin $A$ in the three patients receiving it as a single agent was unequivocal. Whether cyclosporin A or prednisone brought about the response in those treated successfully with the combination remains uncertain. Four patients (Nos 1-4) had deteriorated while having prednisone in a minimum dose of $20 \mathrm{mg} /$ day; hence we conclude that cyclosporin A either was effective in treating them or at least potentiated the effect of the prednisone. Patients 6, 7, and 8 are more difficult to assess, as they had previously responded to prednisone in doses greater than $20 \mathrm{mg} /$ day in addition to immunosuppresants. The combination of relatively low doses of cyclosporin $A$ and prednisone was at least as effective as previous combinations of immunosuppressants had been. Patient 9 had previously been treated with corticosteroids alone and patient 5 had received no previous treatment. A major therapeutic effect of corticosteroids in these two patients cannot be excluded. The response of patient 1 , who had progressive interstitial lung fibrosis with extrapulmonary features of rheumatoid disease, is similar to that of a patient reported previously. ${ }^{16}$

Permanent remission was not achieved after treatment for 24-36 months and relapse after cessation of the combined treatment suggests that indefinite treatment may be indicated. In one patient with a pronounced honeycombing pattern on the chest radiograph combined treatment may have caused sufficient immunosuppression to allow infection to occur. Toxic effects of cyclosporin $\mathrm{A}$ on the kidney can be reversed by reducing the dose, but hypertension in our patients required long term treatment. We do not believe that these complications in some patients preclude the use of low dose cyclosporin $\mathrm{A}$ and prednisone, given the side effects of other immunosuppressant combinations.

The combination of low doses of cyclosporin $A$ and prednisone was effective in some patients with cryptogenic fibrosing alveolitis and in patients with lymphocytic interstitial lung disease with minimal fibrosis; but the limitations of a non-randomised study and small numbers of patients must be taken into account when these results are assessed. More information is required to assess the benefits of combined treatment for an extended period.

This study had financial support from the Medical Research Council of the Republic of South Africa.

1 Snider GL. Interstitial pulmonary fibrosis: clinical features, natural history, and complications. Semin Respir Med 1984;6:71-9.

2 Stack BHR, Choo-Kang YFJ, Heard BE. The prognosis of cryptogenic fibrosing alveolitis. Thorax 1972;27:535-42.

3 Turner-Warwick M, Burrows B, Johnson A. Cryptogenic fibrosing alveolitis: clinical features and their influence on survival. Thorax 1980;35:171-80.

4 Carrington CB, Gaensler EA, Coutu RE, et al. Natural history and treated course of usual and desquamative interstitial pneumonia. N Engl J Med 1978;298:801-9.

5 Crystal RG, Bitterman PB, Rennard SI, et al. Interstitial lung diseases of unknown cause: disorders characterized by chronic inflammation of the lower respiratory tract. [first of two parts]. N Engl J Med 1984;310:154-66.

6 Cantin A, Crystal RG "Interstitial pathology": an overview of the chronic interstitial lung disorders. Int Arch Appl 
Immunol 1985;76(suppl 1):83-91.

7 Kallenberg CGM, Schilizzi BM, Beaumont F, et al. Expression of class II MHC antigens on alveolar epithelium in fibrosing alveolitis. Clin Exp Immunol 1987;67:182-90.

8 Cathcart MK, Emdur LI, Ahtiala-Stewart K, Ahmad M. Excessive helper $T$-cell function in patients with idiopathic pulmonary fibrosis: correlation with disease activity. Clin Immunol Immunopathol 1987;43:382-94.

9 Turner-Warwick M, Burrows B, Johnson A. Cryptogenic fibrosing alveolitis: response to corticosteroid treatment and its effect on survival. Thorax 1980;35:593-9.

10 Keogh BA, Bernardo J, Hunninghake GW, et al. Effect of intermittent high dose parenteral corticosteroids on the alveolitis of IPF. Am Rev Respir Dis 1983;127:18-27.

11 Brown $\mathrm{CH}$, Turner-Warwick $M$. The treatment of cryptogenic fibrosing alveolitis with immunosuppressant drugs. $Q J$ Med 1971;40:289-302.

12 Winterbauer RH, Hammar SP, Hallman KO, et al. Diffuse interstitial pneumonitis. Clinicopathologic correlations in 20 patients treated with prednisone/azathioprine. Am J 20 patients treated with
Med 1978;65:661-72.
13 Meier-Sydow J, Rust $M$, Kronenberger $H$. Diagnosis and therapy of idiopathic pulmonary fibrosis. Allergol Immunopathol 1980;80:101-9.

14 Johnson MA, Kwan S, Snell NJC, et al. Randomised control trial comparing prednisone alone with cyclophosphamide and low dose prednisone in combination in cryptogenic fibrosing alveolitis. Thorax 1989;44:280-8.

15 Hay JG, Turner-Warwick M. Cryptogenic fibrosing alveolitis (idiopathic pulmonary fibrosis): review of certain features leading to new areas of investigation. In: Flenley DC, Petty TL, eds. Recent advances in respiratory medicine. Edinburgh: Churchill Livingstone, 1982: medicine.

16 Gruhn WB, Diaz-Buxo J. Cyclosporine treatment of steroid resistant interstitial pneumonitis associated with dermatomyositis/polymyositis. J Rheumatol 1987;14:1045-7.

17 Oram S. Clinical heart disease. 2nd ed. London: Heinemann, 1984:46.

18 Louw SJ, Bateman ED, Benatar SR. Cryptogenic fibrosing alveolitis—clinical spectrum and treatment. S Afr Med J 1984:195-200. 